\title{
Rainy weather and medical school admission interviews
}

\author{
Donald A. Redelmeier MD, Simon D. Baxter BSC
}

\section{ABSTRACT}

Mood can influence behaviour and consumer choice in diverse settings. We found that such cognitive influences extend to candidate admission interviews at a Canadian medical school. We suggest that an awareness of this fallibility might lead to more reasonable medical school admission practices.

A dmission offers to medical school are competitive and sometimes based on an interview. Psychology research suggests, however, that interviews are prone to subconscious biases from extraneous factors unrelated to the candidate. ${ }^{1}$ One of the most fundamental observations is that people interviewed on rainy days tend to receive lower ratings than people interviewed on sunny days. ${ }^{2}$ We studied whether this bias also extends to admission interviews at a

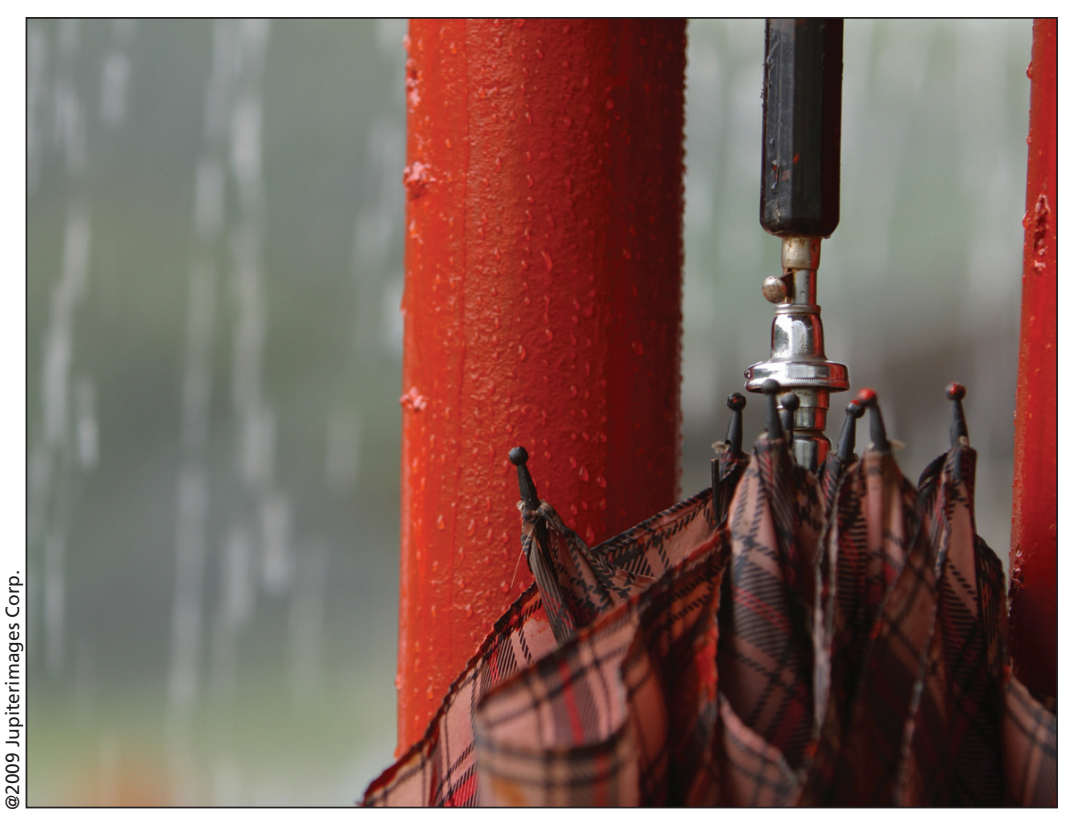
large Canadian medical school.

We analyzed the results of consecutive medical school interviews at the University of Toronto between 2004 and 2009. We included all data available with no exclusions. Almost all interviews occurred in the early spring. Scores for each interview were obtained from the admissions office as recorded from 0 to $20 .^{3}$ This Likert scale was anchored with integer values where 10 denoted "unsuitable," 12 denoted "marginal," 14 denoted "fair," 16 denoted "good," 18 denoted "excellent" and 20 denoted "outstanding."

We obtained weather data from the official government archive and defined a priori the day as "rainy" if precipitation (including freezing rain, snow and hail) occurred in the morning or afternoon. ${ }^{4}$ Otherwise, we defined the day as "sunny." We did not examine more complex combinations with time lags, such as when a sunny day followed multiple rainy days.

A total of 2926 candidates were interviewed over the 6-year period. As expected, their demographic characteristics were unrelated to the weather (Appendix 1, available online at www.cmaj.ca/cgi/content/full/cmaj.091546/DC1). Overall, those interviewed on rainy days received about a $1 \%$ lower score than those interviewed on sunny days (average score 16.31 v. $16.49, p=0.042$ ). This pattern was consistent for both senior interviewers (16.39 v. $16.55, p=0.08)$ and junior

From the Department of Medicine (Redelmeier, Baxter), University of Toronto; the Clinical Epidemiology Program (Redelmeier), Sunnybrook Health Sciences Centre; and the Institute for Clinical Evaluative Sciences (Redelmeier, Baxter)m Toronto, Ont.

Cite as CMAJ 2009. DOI:10.1503/cmaj.091546

interviewers (16.23 v. 16.42, $p=0.041)$. We next used logistic regression to analyze subsequent admission decisions. The difference in scores was equivalent to about a $10 \%$ lower total mark on the Medical College Admission Test.

We suggest that cognitive patterns evident in controlled psychology laboratories can also occur in regular medical settings. The magnitude of the specific influence may be modest, but such small differences can be important in some cases because each year there are about 100 candidates who receive a score within $1 \%$ of the admission threshold. ${ }^{5}$ In this study, we examined only one extraneous influence on mood. Many additional factors may also affect mood (e.g., ambiance, deportment, humour and scent). ${ }^{2}$ Calling attention to these issues may diminish their impact on judgment. ${ }^{1}$

\section{REFERENCES}

1. Schwarz N, Clore GL. Feelings and phenomenal experiences. In: Kruglanski A Higgins ET, editors. Social psychology. Handbook of basic principles. 2nd ed. New York (NY): Guilford; 2007. p. 385-407.

2. Schwarz N, Clore GL. Mood, misattribution, and judgments of well-being: informative and directive functions of affective states. J Pers Soc Psychol 1983;45:513-23.

3. Hensel JM, Shandling M, Redelmeier DA. Rural medical students at urban medical schools: Too few and far between? Open Medicine 2007;1:19-23.

4. Canada's national climate archive. Ottawa (ON): Environment Canada; 2008 Available: http://climate.weatheroffice.ec.gc.ca/ (accessed 2009 Oct. 21).

5. Gladwell M. The tipping point: How little things can make a big difference. Boston (MA): Little, Brown \& Co.; 2000.

Correspondence to: Donald A. Redelmeier, Sunnybrook Health

Sciences Centre, G-151, 2075 Bayview Ave., Toronto ON

M4N 3M5; fax 416 480-6048; dar@ices.on.ca 